\title{
LOS PERVERSOS ESPACIOS-SANTUARIO EN LA NARRATIVA DE CRISTINA FERNÁNDEZ CUBAS ${ }^{1}$
}

\author{
THE PERVERSE SANTUARY-SPACES IN THE FICTION \\ OF CRISTINA FERNÁNDEZ CUBAS \\ Patricia GARCÍA GARCÍA \\ Universidad de Alcalá \\ patricia.garciag@uah.es
}

\begin{abstract}
Resumen: La literatura fantástica de Cristina Fernández Cubas muestra una peculiar inclinación hacia espacios en que ciertos personajes se refugian para distanciarse de un mundo con el que no se identifican. La habitación de Nona (2015) ofrece nuevas perspectivas sobre este tipo de espacialidad que hemos denominado espacio-santuario, recurrente en la producción de la autora desde la publicación de su primer volumen de cuentos en 1980. En este artículo exploramos la doble dimensión de este lugar de protección y alienación apoyándonos en la teoría de los borderscapes, las aportaciones antropológicas referentes al símbolo del santuario y el refugio, y mediante una perspectiva espacial del texto literario que supedita el concepto de trama al de dominio espacial.
\end{abstract}

Palabras clave: Cristina Fernández Cubas. Geocrítica. Santuario. Narrativa fantástica.

\begin{abstract}
Cristina Fernández Cubas's fantastic fiction shows a peculiar preference towards spaces in which certain characters take refuge to distance themselves from a world with which they do not identify. La habitación de Nona (2015) offers new perspectives on this type of spatiality, which we have called sanctuary-space, recurrent in the author's production since the publication of her first volume of stories in 1980. This article explores the double dimension of this place of protection and alienation with the support of the theory of borderscapes, through anthropological contributions regarding the symbol of the sanctuary and refuge and, from a spatial perspective on the literary text that subordinates the concept of plot to that of spatial domain.
\end{abstract}

Keywords: Cristina Fernández Cubas. Geocriticism. Sanctuary. Fantastic fiction.

\footnotetext{
${ }^{1}$ El artículo es resultado del proyecto de investigación Ramón y Cajal RYC2018-024370-I (Dra. Patricia García García), y de los proyectos de investigación Lo fantástico en la cultura española contemporánea (1955-2017): narrativa, teatro, cine, televisión, cómic y radio, del Ministerio de Economía, Industria y Competitividad (FFI2017-84402-P, I.P. Dr. David Roas), y Estrategias y figuraciones de lo insólito. Manifestaciones del monstruo en la narrativa en lengua española (de 1980 a la actualidad, del Ministerio de Ciencia, Innovación y Universidades (PGC2018-093648-B-I00, I.P. Dra. Natalia Álvarez Méndez).
} 


\section{INTRODUCCIÓN}

“QQué encontrará en esta habitación para permanecer aquí durante tanto tiempo?” ("El ángulo del horror”, 2008: 216).

"Poco a poco hizo de su habitación un mundo y yo dejé de tener el menor significado para ella" ("La habitación de Nona", 2015: 18).

"Una habitación. Tan sólo necesitaba una habitación. Por un tiempo" ("Hablar con viejas", 2015: 52).

"Está escondida en su cuarto. Con la puerta abierta... La ha dejado así expresamente, para que ellos crean que no hay nadie en la habitación y la busquen en otro lado" ("Interno con figura", 2015: 64).

Como revelan estas citas, la literatura fantástica de Cristina Fernández Cubas muestra una peculiar inclinación hacia espacios en los que ciertos personajes se refugian para distanciarse de un mundo con el que no se identifican. Desde Mi hermana Elba (1980) hasta La habitación de Nona (2015), estos santuarios atraviesan la poética espacial en la narrativa de la autora. Aislados geográficamente, como el internado de "Mi hermana Elba" o la casa de "Días entre los Wasi-Wano", o en una ciudad, como "La habitación de Nona" o "El ángulo del horror", son espacios que albergan identidades sometidas a una experiencia fantástica que subvierte los códigos de la realidad cotidiana. Esos personajes "fuera de lo común" ("El lugar", 2008: 304), con algo "especial" ("Mi hermana Elba", 2008: 68 y "La habitación de Nona", 2015: 15, 17, 35) se construyen una morada condenada por el resto por tratarse de un mundo propio, excluido y excluyente, que reivindica su alteridad. En este artículo exploramos la doble dimensión de este lugar de protección y alienación, que hemos denominado "espacio-santuario", apoyándonos en la teoría de los borderscapes (Schimanski, Rosello y Wolfe, 2017, y Rosello y Wolfe, 2017), las aportaciones antropológicas referentes al símbolo del santuario y el refugio y, siguiendo a Marie-Laure Ryan (1991) y Ludomír Doležel (1998), mediante una perspectiva geocrítica del texto literario que supedita el concepto de trama al de dominio espacial.

El volumen de cuentos La habitación de Nona, galardonado con el Premio Nacional de la Crítica el mismo año de su publicación y el Premio Nacional de Narrativa un año más tarde, ofrece un catálogo diverso de estos espacios-santuario. Exploraremos dos variaciones simbólicas representadas en "La habitación de Nona" y "Días entre los WasiWano”. Siguiendo los presupuestos de Doležel en Heterocósmica, analizaremos la construcción de la trama mediante la dinámica de mundos narrativos. Leídos bajo esta perspectiva, los relatos seleccionados combinan tres modalidades distintas: la epistémica, con el motivo del enigma y del secreto oculto en el espacio-santuario, la alética, que yuxtapone el dominio natural al de lo sobrenatural, y la axiológica, marcada por mundos 
narrativos con sistemas de valores antagónicos. En el último apartado mostraremos cómo estas tres variantes dialogan con otros relatos de la autora.

\section{LOS ESPACIOS FANTÁSTICOS DE CRISTINA FERNÁNDEZ CUBAS}

Cristina Fernández Cubas es considerada una de las voces españolas más importantes en el desarrollo de la narrativa fantástica contemporánea. A su primer volumen de cuentos, Mi hermana Elba (1980), que inicia el auge y normalización lo fantástico en España (Roas, Álvarez, García, 2017: 195-199), le sigue una activa producción literaria marcada por elementos insólitos que remiten a la tradición fantástica ${ }^{2}$.

La crítica ha enfatizado el motivo recurrente del desdoblamiento en sus variantes: gemelas y gemelos, dobles y alter ego en "Helicón", "Los altillos de Brumal", "Cris y Cros" y "La habitación de Nona"3. Desde una perspectiva feminista de la que en ocasiones la autora se ha distanciado, algunos estudios se han centrado en el motivo del viaje fantástico como expresión de la búsqueda femenina de una identidad más allá del sistema patriarcal (Talbot, 1989; Folkart, 2000; Roas, 2019). Asimismo, se ha señalado la influencia de la espacialidad gótica, en particular en lo relacionado con el topos del encierro. Zatlin, por ejemplo, hace referencia a algunas de las historias más conocidas, como "Mi hermana Elba", "Los altillos de Brumal", "La mujer de verde" o "El lugar", y señala la tendencia de las protagonistas a dar la espalda al mundo y aislarse: "[they] are subjected to all manner of mistreatment by doubles and other malevolent forces and have a disconcerting tendency to turn their backs on worldly success or supposedly normal lives by retreating to Gothic enclosures or death" (Zatlin, 1996: 37). En la espacialidad de la obra de Cristina Fernández Cubas también se aprecia la influencia de autores clásicos del terror y lo grotesco, como Edgar Allan Poe, en la construcción atmosférica ("La noche de Jezabel”, véase Roas, 2007) y en los espacios claustrofóbicos (como la residencia aislada de "La ventana del jardín", el internado de "Mi hermana Elba" y el convento de "Mundo"). La autora además ha rendido un homenaje explícito al escritor norteamericano en su versión del relato inconcluso "El faro" (véase García, 2015).

Partiendo de la base geocrítica que aportan estos estudios, en el presente artículo nos centramos en el motivo del espacio-santuario, que presenta atributos próximos al "third space" de Homi K. Bhabha (1994: 55, 245). Sin el marco postcolonial que motiva a Bhabha a formular este conocido concepto espacial, entendemos estos espacios-santuario como zonas fronterizas o borderscapes que generan identidades alienadas e híbridas donde "the negotiations of incommensurable differences create a tension peculiar to border-line existences” (Bhabha, 1994: 218). Con más complejidad que las figuras góticas del encierro ya trabajadas por la crítica en la obra de Cristina Fernández Cubas,

\footnotetext{
${ }^{2}$ En cuanto a lo fantástico y lo insólito en La habitación de Nona, véase el estudio de Andres-Suárez (2016). Sobre intertextualidad, arquetipos y lo fantástico en las figuras femeninas de Cristina Fernández Cubas, en concreto en "La habitación de Nona", véase Nuñez de la Fuente (2019).

3 Dentro del marco de los Disability Studies, Folkart (2019) ha abordado el motivo del doble como afirmación de la diferencia física y psíquica que subvierte el discurso normativo neoliberal.
} 
el espacio-santuario aglutina una constelación de motivos: la fundación de límites que demarcan este refugio, los mecanismos de defensa e intrusión, el suspense dictado por el secreto y la ambivalencia simbólica del escondite, como refugio y exclusión. En los apartados que siguen intentaremos demostrar que los espacios-santuario en la obra más reciente de Cristina Fernández Cubas no se limitan a proveer el trasfondo de la acción. Estos espacios narrativos son elementos activos tanto en el proceso de caracterización de los personajes como en la conformación dinámica de la trama.

\section{3. "LA HABITACIÓN DE NONA": EL SANTUARIO COMO BORDERSCAPE}

"La habitación de Nona", con referencias directas y recurrentes al motivo del santuario, es el texto modelo para estudiar la configuración de este símbolo. En primera persona, una niña cuyo nombre desconocemos hasta el final describe la difícil relación que mantiene con su hermana pequeña, Nona, quien desde que empezó a crecer se recluye en su habitación. Este "santuario" (2015: 19, 23, 32) está protegido por una serie de umbrales mediante los cuales Nona puede controlar el acceso ajeno. El relato de la narradora se centra en los distintos intentos de acceder a la habitación de Nona, con el fin de averiguar qué oculta ese misterioso lugar.

Al principio del cuento Cristina Fernández Cubas introduce unas marcas de incertidumbre atribuidas a la memoria que ponen en duda la veracidad de los hechos narrados ("falsos recuerdos", "engañosas memorias", "recuerdo inventado" o "elaborado", 2015: 15). Esta desconfianza que el testimonio de la protagonista infunde en el lector aumenta a medida que se vislumbra la disonancia entre cómo la narradora percibe a su hermana y lo que su entorno opina de esa relación filial. En la última escena la no fiabilidad del testimonio de la narradora culmina al confirmarse el desdoblamiento de su identidad: Nona y ella no son dos personas sino una sola. Sin embargo, alterando los presupuestos clásicos del motivo del doble, el cuento no se resuelve con esta revelación. En una última vuelta de tuerca, no se anula el objeto imaginario (el doble, su hermana Nona) sino el sujeto que lo imagina: “"Tú no eres nadie. Sólo una proyección de Nona. Una invención. Su hermana imaginaria..." (2015: 43-44) ${ }^{4}$. De este modo la protagonista descubre finalmente que no se ha inventado la existencia de Nona sino que ha proyectado la suya en una hermana Nona imaginaria para no admitir los cambios que ha experimentado al crecer en un cuerpo que no reconoce.

Este descubrimiento nos obliga a releer todo el cuento desde un nuevo marco interpretativo. Si la construcción del suspense durante todo el relato se había centrado en la figura de Nona encerrada en ese cuarto misterioso, el desenlace resitúa el foco en la

\footnotetext{
${ }^{4}$ El motivo del doble tal como está presentado en este relato enmarcaría este cuento en la categoría de lo "pseudo-fantástico" (Roas, 2011: 62-67). El desdoblamiento de la identidad en este caso, más que como realidad física, obedece a un mecanismo de disociación psicológica como resultado de la discapacidad psíquica de la protagonista.
} 
narradora y en su relación con esa imaginaria habitación de Nona. Este espacio, central en el discurso de la protagonista, es el eje que nos permite comprender los procesos de desdoblamiento de la identidad, huida de la realidad y protección de la mirada ajena. "Su nuevo cuarto" (2015: 17) se convierte en un mundo en que Nona se recluye; un "santuario" que no quiere compartir y que celosamente custodia.

En sus trabajos sobre la estética de lo liminal, Schimanski y Wolfe (2017), y Rosello y Wolfe (2017) proponen el concepto de borderscapes, de gran utilidad para comprender las funciones estructurales y dimensiones simbólicas del espacio santuario en "La habitación de Nona". Combinando el "third space" de Homi Bhabha (1994) con la teoría de "scapes" pronunciada por Ajun Appadurai (1990), los borderscapes son zonas de contacto y negociación de identidades y representan la expresión artística de la experiencia de la frontera. Este marco conceptual nos permite abordar esos espaciossantuario en la ficción fantástica de Cristina Fernández Cubas, como son la habitación de Nona, los escondites de "Mi hermana Elba", la casa en la aldea de "La ventana en el jardín" o el altillo en "Los altillos de Brumal", no como lugares circunscritos a un marco geográfico y temporal sino como prácticas imaginativas, zonas dinámicas que surgen de una experiencia liminal (entre lo real y lo imaginario, entre presente y pasado, entre identidad y otredad, entre etapas vitales, entre protección y reclusión). Esta construcción del lugar hace referencia a lugares fronterizos que el sujeto "entre-fases" crea motivado/a por una necesidad de establecer su propio territorio íntimo.

\subsection{Rituales de demarcación y defensa}

Los borderscapes derivan de procesos de diferenciación. Esta actividad, que se caracteriza por la separación del resto del mundo a través de un sistema de límites, hace referencia a la acción más primitiva de articular el cosmos a partir del caos, y con ello con el origen de producir un espacio humano ${ }^{5}$. Anke Strüver designa este proceso con el término de borderscaping: "practices through which the imagined border is established and experienced as real" (2005: 170).

En el caso de "La habitación de Nona" la fundación del santuario ocurre en el momento en que la hermana de la narradora cumple cuatro años. Hasta entonces, según el testimonio de la protagonista, las dos jugaban y dormían juntas. Sin embargo, su hermana empezó a comer mucho, a crecer, y en ese momento se le asignó un cuarto para ella. Empieza entonces la escisión, en la que Nona se inventa a una hermana homónima

\footnotetext{
${ }^{5}$ Véase la lectura que O. F. Bollnow realiza del imago mundi de Mircea Eliade en cuanto a la creación del hogar como rito de fundación del espacio sagrado: "The world as a whole is mirrored in the house. And for this reason every house that is built, and even more so every temple that is built, is a repetition of the creation of the world, a reconstruction of the work done by the gods at the beginning of time. For this reason all human ordering of space is 'only repetition of a primordial act, the transformation of chaos into cosmos by the divine act of creation'. This is true particularly of the human house: '[The house] is the universe that man constructs for himself by imitating the paradigmatic creation of the gods, the cosmogony" (Eliade en Bollnow, 2011: 137).
} 
y proyecta todos sus defectos en ella. Para ello, en un proceso de demarcación espacial de la otredad, genera un espacio único para su hermana que la aparta del resto; una esfera propia (Eigenspähre, Bollnow, 2011: 130-131). Los estudios de la frontera (border theory) que se centran en el limes como práctica de distinción identitaria lo han denominado b/ordering, aludiendo a la doble dimensión de bordering y othering: "This is based on the fear of living with the 'other', of wanting the self to be here, and the other to be there, with a clear border separating the activity and interaction spaces of the two" (Newman, 2006: 176-177, véase también Van Houtum y Van Naerssen, 2002 y Van Houtum et. al., 2005). Esta habitación, a la que solo su hermana imaginaria tendrá acceso, alberga el proceso de formación de la alteridad, esa "diferencia" que se repite como eufemismo a lo largo del relato.

El antropólogo alemán O. F. Bollnow, bajo la clara influencia de los análisis fenomenológicos de los espacios íntimos pronunciados por Heidegger, Merleau-Ponty y Bachelard, subraya que el acto de habitar un espacio expresa la dimensión existencial del ser en el mundo. Bollnow ilustra esa simbiosis entre habitar y existir mediante el término alemán de Wohnzimmer (salón, el lugar que ocupa la familia), que combina wohnen (vivir) y Zimmer (habitación), literalmente "habitación para vivir" (2011: 122). Estos estudios reiteran que la creación de un espacio en el que el sujeto se sienta protegido - el hogar - es la función principal y primitiva de habitar. La fundación de este refugio obedece al acto de trazar fronteras, o mejor dicho de imaginarlas (borderscaping) a través de la experiencia del espacio: "By means of the walls of the house, a special private space is cut out of the large common space, and thus an inner space is separated from an outer space" (Bollnow, 2011: 125). Si el refugio ofrece seguridad y protección de la amenaza exterior, en el caso de "Mi hermana Elba" la demarcación exterior-interior no responde a los límites de la casa porque Nona no necesita protegerse en la casa sino de la casa.

Evocando a Heidegger, Bollnow nos recuerda que el espacio-refugio necesita ser delimitado y defendido: "the 'Frieden' [peace] in which one lives is related to the 'Umfriedung' [enclosure] of the dwelling area. So in order to dwell in peace, we need protective walls and a sheltering roof' (2011: 124). Nona delimita el espacio de su habitación y sitúa ahí la percepción de sí misma que no quiere o no puede asumir. A partir de ese momento ella observa ese lugar desde fuera. Su hermana imaginaria, en su nuevo rol de guardiana del umbral, protege el santuario de las intrusiones: "mi hermana era como el dragón que protegía un tesoro. Rodeaba cuan largo era su santuario y lo preservaba de miradas ajenas" (2015: 23). Esta imagen se reitera: Nona "recluida en su feudo" es "el dragón que custodia un tesoro" (2015: 31) y dicta quién tiene acceso a su habitación y en qué condiciones. Crispi, la mujer que ayuda en las tareas del hogar, es la única autorizada a entrar para limpiar una vez por semana, acto que Nona considera una profanación: "aceptar que un intruso acababa de profanar su santuario y hacer como si nada hubiera ocurrido" (2015: 19).

El espacio que su hermana imaginaria habita, ese misterioso cuarto, es un mundo inaccesible para la narradora: Nona "es la reina de un mundo que no vemos" (2015: 30). 
En una de las escenas iniciales, esta exclusión se refleja con un juego de deícticos que desarticulan los referentes espaciales del aquí y allí:

Yo a menudo golpeaba con los nudillos, empujaba la puerta $[\ldots]$ y lo único que lograba sorprender era la cara transfigurada de Nona, perdida o soñadora, como si no estuviera allí, en su cuarto, sino a miles de kilómetros o más. En otro planeta. [...] lejos, muy lejos, en ese mundo secreto que no quería compartir (2015: 19).

Esa simultánea negación y afirmación de la presencia —el "no estar allí" para el resto- es un mecanismo presente en relatos fantásticos anteriores en los que también aparece un espacio que protege a las protagonistas de la mirada ajena, como ocurre en "Mi hermana Elba" ("Estábamos allí pero no estábamos. Y aunque a ti te pudiese parecer que estábamos, no estábamos”, 2008: 65).

\subsection{El secreto}

Chevalier y Gheerbrandt definen el símbolo del santuario como un espacio construido para proteger la existencia de lo oculto: "This is the name applied to a place which is set apart, taboo, and enshrining some basic treasure" (1996: 824). En "La habitación de Nona" la dimensión simbólica del secreto fragua la trama en tanto que la habitación representa un misterio que la narradora deberá resolver: "todo lo que ocurría en el interior del dormitorio es un suponer” (2015: 19), “¿Qué tendrá esa habitación para que se encuentre tan a gusto?" (2015: 24). Ese secreto, característico de las configuraciones ficcionales de modalidad epistémica (Doležel, 1998: 126-128), es el motor de la historia. La narradora observa el cuarto desde fuera, desde la perspectiva de alguien para quien la verdadera identidad de Nona supone un misterio impenetrable. Los límites demarcados por Nona - la puerta por ejemplo, infranqueable sin su permiso - estructuran el suspense en las distintas escenas. Como nos recuerda Newman en su influyente estudio dedicado a la border theory, "if a border exists, there is always someone who wants to cross it to get to the other side" (2006: 178). La narradora, convertida en detective, logra en varias ocasiones entrar en la habitación. Se atribuye la misión de trasgredir esos accesos custodiados por su hermana, "encontrar un resquicio, una rendija para introducirme en la habitación prohibida" (2015: 31), "burlar su vigilancia y penetrar en el santuario con la mayor tranquilidad del mundo" (2015: 31). Esta misión se despliega en varias etapas. Primero la protagonista busca una manera de penetrar en ese misterioso mundo a través de "una puerta o rendija por la que entrar en la habitación prohibida y desvelar sus misterios" (2015: 23). Lo que queda velado a la vista por esa puerta que su hermana protege es desvelado por el sonido. La narradora reitera que el oído es su gran aliado, pues sortea esos umbrales y se filtra por la pared que divide su habitación de la de Nona. "Con el oído pegado a la pared" (2015: 25), "escuchando a través de la pared" (2015: 29) esas "voces que salían de su cuarto la noche anterior" (2015: 28) descubre detalles que Nona oculta, como su grupo de amigos imaginarios con quienes comparte su vida. 
Cristina Fernández Cubas hábilmente pospone la resolución de ese misterio atribuido a la existencia de la habitación. Cuando logra por fin entrar en la habitación porque "nadie vigilaba el santuario" (2015: 32), la narradora establece decepcionada que ese cuarto no tiene nada de especial a simple vista. Sin embargo, en ese espacio "ordenado y pulcro", “impersonal" y "anodino" (2015: 32), en esa "habitación como tantas otras" (2015: 33) permanece "el inconfundible olor a Nona" (2015: 34).

En la última incursión, que lleva al desenlace, la narradora comprende que ese espacio ha sido una estrategia para evitar enfrentarse a su propio proceso de crecimiento y a su discapacidad psíquica. En esta escena final el santuario se configura como dominio de lo prohibido y se ponen de manifiesto los atributos de la modalidad deóntica (Doležel, 1998: 120-123). La narradora repite la palabra "vergüenza" y subraya las "cosas que no se pueden revelar a los padres" (2015: 38), aquello que da "una vergüenza horrible" (2015: 38). Además de ser un espacio para abstraerse del entorno, la habitación sirve para ocultar aspectos relacionados con su sexualidad.

En un gesto simbólico que refleja un rito de pasaje hacia una identidad nueva, la narradora entra finalmente "en el santuario con paso firme" (2015: 44). Ese cruce del umbral le obliga a someterse a la realidad de Nona desde el otro lado de la frontera, desde dentro. Con las fotos modificadas que muestran a su psicólogo desnudo la narradora empieza a recordar, "a ver en el recuerdo", "a rescatar momentos" (2015: 40). Al tomar consciencia de que "ella es la única que existe" (2015: 42), abandona su función de observadora y pasa a reconocerse como fundadora de ese espacio que la refugia de las cualidades que no ha querido o podido asumir. Sin embargo, el inesperado uso del pretérito imperfecto introduce una nueva sorpresa. El desdoblamiento seguido de la revelación no ha ocurrido una sola vez sino muchas. Incluso se sugiere que volverá a ocurrir: "Este era el final. El final que no recordaba. El final que me perseguía en sueños. La eterna pesadilla. Pero luego, al despertar, las cosas se ordenaban y volvían a ser como antes" (2015: 41).

En un estudio sobre la figura del santuario y sus manifestaciones literarias, Hugo Walter nos recuerda que este espacio simbólico es creado para aplacar la angustia que provoca el paso del tiempo: "The idea of a sanctuary and the desire to create or participate in a sanctuary are motivated to some extent, if not to a considerable extent, by a profound concern about and by an acutely sensitive response to time and the inevitability of mortality" (2010: 6). La fundación del santuario es un gesto que aspira al infinito, en un intento de transgresión de los límites impuestos por la finitud humana. Esta idea es desarrollada por el antropólogo Gilbert Durand en referencia a los símbolos que actúan como "antídoto del tiempo" (1992: 187) a través de la fundación de espacios de la intimidad que reflejan una constancia eterna. Espacios cerrados como la tumba, la cueva o el hogar o la habitación surgen de la necesidad de protección frente al horror que provoca el transcurso del tiempo y se nutren de una "profunda claustrofilia" (1992: 230). Durand hace hincapié en la circularidad de estos símbolos que reflejan lo eterno en su aproximación a lo sagrado: 
The sacred space has the power to be indefinitely multiplied. Historians of religion comment on the ease with which "centres" are multiplied, and on the total ubiquity of the sacred [...]. In this way ma demonstrates his capacity to renew himself, and the sacred space becomes the prototype of sacred time. The dramatisation of time and the cyclical processes of the temporal imagination only follow, it seems, the primordial exercise of spatial replication (1992: 241).

La revelación final en "La habitación de Nona" genera un efecto circular que anula el relato lineal que primaba hasta entonces. La historia de Nona se repite en el tiempo. Esta lógica rompe con la estructura de la trama que dictan los mundos de la modalidad epistémica cuando se resuelve el misterio. En el texto de Cristina Fernández Cubas la última escena nos remite al principio. Con un giro a este relato de dobles y proyecciones imaginarias de la alteridad inasumible, la autora establece una perversa recurrencia que anula el efecto climático de la revelación de la identidad de Nona. La escisión se vuelve a materializar y Nona deviene de nuevo dos personas diferenciadas por esa habitación, en un acto de desplazamiento que ya ha "vivido antes, no una sola vez, sino varias" (2015: 44). Para escaparse de un cuerpo en el que no se reconoce crea un lugar a salvo que le permite "contemplarlo desde fuera" (2015: 44). La narradora vuelve a su rol de hermana observadora y restituye ese espacio que alberga una identidad que no es capaz de asumir. Ese misterioso santuario, distinguido del resto de la casa y blindado contra los demás, se reconfigura una vez más como "la habitación de Nona".

\section{4. "DÍAS ENTRE LOS WASI-WANO" Y LA COEXISTENCIA INSÓLITA DE REALIDADES ESPACIALES}

El último relato del volumen sintetiza aspectos analizados en la sección anterior en relación con la existencia de un espacio imaginario de protección y evasión ("La habitación de Nona") y nos ofrece una estructura espacial basada en la modalidad alética, en la que lo real dialoga con lo sobrenatural (Doležel, 1998: 115-120). Dos mundos coexisten en una casa cerca de una aldea remota: el dominio de lo natural (el espacio doméstico) y el de lo insólito (la selva de los Wasi-Wano) se confabulan de forma imposible en un mismo espacio.

En "Días entre los Wasi-Wano" la protagonista recuerda sus aventuras durante un verano cuando tenía trece años, cuando fue con su hermano a pasar una temporada a casa de sus tíos, Tristán y Valeria, quienes vivían en la montaña recluidos del pueblo más cercano. El peculiar estilo de vida de sus tíos, "los Viva la Virgen" (2015: 137) misteriosos y aventureros, generaba desaprobación de los otros familiares, pero instigaba mucha curiosidad en la protagonista. Alejada del contacto humano, la casa de Tristán y Valeria constataba esa percepción. Era un espacio de libertad: "A su lado cualquier otro hogar parecía una prisión, un zoo" (2015: 138). En ese "mundo secreto" (2015: 142) Tristán inició a sus sobrinos en los ritos ancestrales amazónicos y los introdujo en la vida 
de la marginada y misteriosa tribu de los Wasi-Wano. Las enseñanzas de Tristán ese verano permitieron a la narradora transportarse a ese "espacio suspendido en el tiempo" (2015: 169) "con sólo cerrar los ojos" (2015: 169). Una gran pelea entre Tristán y Valeria a la aventura con los Wasi-Wano y la narradora y su hermano regresaron a casa de sus padres.

En este relato observamos la yuxtaposición de dos mundos que no pueden coexistir y que, sin embargo, de forma insólita, lo hacen: por una parte, el mundo de los adultos, de la cotidianidad y de la normalización (personificada especialmente por el personaje de la tía Berta) y, por otra, el espacio de la selva amazónica que los tíos convocan por las noches. El desenlace sugiere que el espacio de liberación y aventura construido por Tristán y Valeria en su "voluntario aislamiento" (2015: 166) existe para no enfrentarse a su relación disfuncional (2015: 162). La correspondencia entre ambos dominios queda reflejada en el motivo del espejo: "Nos enteramos enseguida de que casi todo lo que se da en nuestras tierras tiene su equivalente en las suyas" (2015: 163), así como con la ambigüedad de los deícticos "aquí" y "allí": "Vivimos allí —susurró a mi oído-. Ellos están con nosotros..." (2015: 163). Este mecanismo, ya identificado en "La habitación de Nona", desdibuja el referente geoespacial y pone de relieve la dimensión psicoespacial del espacio-santuario. Más que vivir en un lugar físico identificable en el mapa, los WasiWano son "un estado de ánimo" (2015: 170). Esto explica que en la reflexión final la protagonista se refiera a ese mundo como un valioso legado ofrecido por su tío, quien le regaló "en herencia su bien más querido" (2015: 186), "la llave de un mundo secreto" (2015: 183). "El fabuloso y secreto mundo de los Wasi-Wano" (2015: 186) perdura en ella tras ese verano, y continúa ofreciendo un espacio en el que resguardarse, cuando es necesario, de los conflictos del ordinario mundo de los adultos.

En otro relato de la colección, "Hablar con viejas", el santuario también se construye en torno a dos dominios que contrastan, si bien dentro de los códigos del realismo. Más breve que los cuentos que acabamos de analizar, este texto ilustra la inversión de las características positivas del símbolo del santuario. Dos dominios coexisten: un piso aparentemente normal del Ensanche catalán y la jaula del monstruo. A través de la inesperada revelación de este segundo dominio, el espacio positivizado del espacio doméstico invierte su simbología. El lugar que prometía inicialmente ser refugio para la protagonista se transforma en cárcel y ese perverso golpe de efecto demuestra que las apariencias engañan.

El cuento relata las peripecias de Alicia, una joven que está a punto de ser expulsada de su piso en Barcelona y necesita desesperadamente un techo para refugiarse. Tras el intento frustrado de conseguir dinero a través de un antiguo amigo, se topa con una anciana que solicita su ayuda para cruzar la calle. En agradecimiento, esta anciana solitaria, dulce y pudiente la invita a continuar la conversación en su piso del Ensanche. Alicia se proyecta viviendo en ese gran apartamento que la rescataría del inminente desahucio. Después de una conversación cortés y vacua, de repente la anciana le muestra a su hijo escondido en la galería, un hombre monstruoso que se entretiene con "muñecas 
de carne" (2015: 55): "Un hombretón deforme agarrado a unos barrotes la miraba con la boca babeante. Era un monstruo. Una bestia. Un gigante. Tenía la cabeza abombada, los ojos sin expresión, el rostro lleno de pústulas..." (2015: 55). Con esta revelación final se invierte la relación utilitaria que sugería el comienzo del cuento. Alicia no va a servirse del piso de la anciana para solucionar sus problemas, sino que desde el principio ha sido engañada por la anciana para llevarla a la boca del lobo.

Como ocurre con otros personajes en las ficciones de la autora, especialmente con Clarisa en "El lugar", la protagonista de este relato se distingue por la necesidad de encontrar un espacio propio. En el caso de Alicia en "Hablar con viejas" esto se refleja de forma explícita describiéndola como alguien en situación "desesperada" (2015: 48), con las referencias a "la inminencia del desahucio" (2015: 49) y a su condición de desamparada: "Ya no tenía a quién acudir" (2015: 51), "se encontraría en la calle" (2015: 51), "La vieja, por lo menos, tenía casa" (2015: 50), "Una habitación. Tan sólo necesitaba una habitación" (2015: 52). Al entrar en el comedor, la anciana afirma: "Esta es tu casa" (2015: 51). Esta aparente fórmula de cortesía anticipa el desenlace. Alicia pasa de imaginarse como el sujeto que felizmente va a ocupar ese "piso típico del Ensanche" (2015: 50) a saberse objeto de placer del monstruo encerrado en su macabra cárcel. Se despierta más tarde ya prisionera de ese piso, sabiendo que "no estaba en su cuarto, entre las sábanas de la cama, sino echada en un jergón en el interior de una jaula inmensa" (2015: 56) arrullada por el monstruo "como a un bebé. Como a una muñeca querida" (2015: 56). La caracterización de la anciana también se invierte con la revelación de esta galería oculta en la penumbra del salón del típico piso del Ensanche. Aparentemente indefensa y dulce, esa "vieja encantadora" (2015: 50) demuestra ser cazadora de mujeres jóvenes para entretener a su hijo.

\section{TRES MODALIDADES DEL ESPACIO-SANTUARIO Y SU REPRESENTACIÓN MÁS ALLÁ DE LA HABITACIÓN DE NONA}

Los relatos analizados articulan la alteridad en un dominio exclusivo, marginal y oculto que hemos denominado espacio-santuario. En "La habitación de Nona", la protagonista rechaza su discapacidad y las marcas del paso del tiempo sobre su cuerpo encerrando a una hermana imaginaria en una habitación. Este relato funciona como referente de los aspectos simbólicos y estructurales del santuario en relación con la construcción de umbrales, así como con la doble función de refugio y exclusión. En "Días entre los Wasi-Wano" el mundo salvaje de esta tribu ofrece una aventura más allá de la cotidianidad y normalización adulta y pone de manifiesto la dimensión psicogeográfica del refugio al margen de los conflictos propios de las relaciones adultas.

Hemos subrayado que los espacios analizados no funcionan como contenedores pasivos de la trama sino como dominios y por ello son el motor que configura el suspense y los puntos de inflexión en la trama. Siguiendo a Doležel, podemos afirmar que estos espacios posibilitan las acciones de la historia: "stories happen, are enacted in certain 
kinds of possible worlds. The basic concept of narratology is not "story," but "narrative world," defined within a typology of posible worlds" (Doležel, 1998: 31). Esta última sección se centra en este aspecto para ilustrar la estructura de otros espacios-santuario en ficciones fantásticas previamente publicadas por la autora.

\subsection{Modalidad epistémica: espacio y el secreto}

"La habitación de Nona" representa los textos en los que predomina la modalidad epistémica, articulada alrededor del eje conocimiento-ignorancia, que se centra en lo que la protagonista (no) sabe y cómo esto afecta a la interacción con los demás: "The person's practical reasoning and, consequnetly his or her acting and interacting are to a high degree determined by this epistemic perspective, by what the agent knows, is ignorant of, and believes to be the case in the world" (1998: 126). Esta modalidad, nos recuerda Doležel, genera trama ("story-generating energy", 1998: 126) instigada por la distribución desigual del conocimiento entre los personajes: "The epistemic imbalance produces the basic epistemic narrative, the story with a secret (mystery story): something that happened in the fictional world remains unknown to (some of) its inhabitants, or they have false beliefs about it" (1998: 126). El desequilibrio epistémico en el mundo narrativo se traduce en los motivos del secreto, el enigma y el auto-engaño (1998: 126-127) que alberga la habitación de Nona.

Las historias de "La ventana del jardín" (1980) y de "El ángulo del horror" (1990) también se nutren de estos motivos epistémicos adscritos a unos espacios que los personajes utilizan para refugiarse, abrumados por nuevas experiencias desconcertantes cuya lógica no logran descifrar. En "La ventana del jardín" el narrador se desplaza a la casa de unos antiguos amigos, "una granja abandonada a varios kilómetros de una aldea" (2008: 43) desde la cual mantienen escaso contacto con el mundo externo. Esta "intromisión" (2008: 45) en la reclusión doméstica de sus amigos Josefina y José le desvela un macabro experimento. Allí el matrimonio oculta a su hijo Tomás, quien sufre de una discapacidad indefinida y para quien han inventado un código lingüístico distinto al nuestro. En escenas localizadas en umbrales como la ventana o la reja el protagonista se centra en descifrar el porqué de ese experimento:

A partir de aquel momento los dos empezamos a comprender lo que ocurría a ambos lados de la reja. No fue el encuentro de dos mundos distintos y antagónicos, sino de algo mucho más inquietante. El lenguaje que había aprendido Tomás desde los primeros años de su vida — su único lenguaje - era de imposible traducción al mío, por cuando era EL MÍO sujeto a unas reglas que me eran ajenas (2008: 50).

Debían existir otras causas o, por lo menos, alguna razón oculta en el pasado de mis amigos (2008: 51).

La indagación epistémica con la que Doležel define esta modalidad (1998: 126) se manifiesta con mayor intensidad a medida que la trama avanza. En la escena final el 
protagonista intenta liberar al niño de aquel perverso mundo, acto de transgresión del espacio-santuario que provoca una crisis de salud en el niño. Entonces el protagonista formula una serie de preguntas sin respuesta al terminar el relato y que reflejan su desasosiego (y el de el/la lector/a) al no poder resolver el enigma que supone el mundo que sus amigos José y Josefina han construido para su hijo:

¿Qué estaba pasando? ¿Por qué minutos atrás me sentía como un héroe y ahora deseaba ardientemente vomitar, despertar de alguna forma de aquella pesadilla? ¿Por qué el mismo muchacho que horas antes me pareció rebosante de salud respondía ahora a la descripción que durante todo el día de ayer me hicieran de él sus padres? ¿Por qué, finalmente, ese lenguaje, del que yo mismo — con toda seguridad único testigo- no conseguía liberarme mientras José y Josefina reanimaban a su hijo entre sollozos? ¿Por qué? Me así con fuerza del brazo de José. Supliqué, gemí, grité con todas mis fuerzas. “¿POR QUÉ?”. Volvía a decir [...]. (2008: 53-54).

El cuento fantástico de "El ángulo del horror" empieza con un adolescente, Carlos, "encerrado con llave en una habitación oscura" (2008: 213) en casa de su familia. Por elección propia se refugia allí de una experiencia insólita y terrorífica que ha tenido lugar al volver después de pasar el verano en Inglaterra: sin poderlo evitar, su casa se le muestra desde un ángulo distinto, "el ángulo del horror", como indica el título. El relato se centra en la búsqueda epistémica de Julia, "actuando como una ridícula espía aficionada" (2008: 216) para comprender lo que obliga a su hermano a permanecer recluido en "aquella habitación en sombras" (2008: 216). En esta necesidad de respuestas instigada por el misterio que oculta el cuarto de Carlos observamos formulaciones paralelas a las de la narradora de "La habitación de Nona”: “'La habitación', pensó, ‘¿qué encontrará en esta habitación para permanecer aquí durante tanto tiempo?’” (2008: 216).

\subsection{Modalidad alética: espacio y lo sobrenatural}

El cuento "Días entre los Wasi-Wano" ilustra la modalidad alética, configurada por el eje posible-imposible. El uso de lo insólito representa la modalidad B, según Doležel, que aporta a algunos personajes del dominio natural capacidades imposibles de las que carecen el resto de personajes de este mundo realista, en este caso el viaje nocturno a la tribu amazónica: "Selected natural-world persons are granted properties and action capacieites that are not available to ordinary persons of that world: becoming invisible, flying on a carpet, and so on" (1998: 116).

"Mi hermana Elba" (1980) también refleja esta estructura alética. La narradora nos cuenta sus peripecias junto a su hermana Elba y su amiga Fátima en el internado durante su infancia. Allí descubren unos huecos sobrenaturales en el recinto que las hacen invisibles ("endowed with properties and action capacities that are denied to persons of the natural world", Doležel, 1998: 116). Esconderse en esos lugares les aporta una sensación de liberación de la monotonía del colegio y les permite sortear las estrictas normas que rigen en ese lugar. En estos “mundos sin límites” (2008: 67), “conductos cuya 
comprensión se [les] escapaba" (2008: 67), gracias a estos espacios-santuario pueden desplazarse por las zonas prohibidas del internado.

El relato "El lugar" (1994) responde también a una configuración alética que combina el mundo real con el sobrenatural. El discurso del narrador se centra en su esposa, Clarisa, huérfana y obsesionada con encontrar un lugar:

El lugar, para Clarisa, era algo semejante a un talismán, un amuleto; la palabra mágica en la que se concentraba el secreto de la felicidad en el mundo. [...] Lejos del lugar - en sentido espacial o en cualquier otro sentido - se hallaba el abismo, las arenas movedizas, la inconcreción, el desasosiego (2008: 301).

Tras no superar una enfermedad, Clarisa es enterrada en el panteón de la familia del narrador. Ese lugar al que Clarisa ansiaba permanecer después de la muerte genera una serie de conflictos entre ella y la familia difunta del narrador. Desde el dominio de los muertos, Clarisa se le aparece reiteradamente en sueños hasta que asume su "inútil pretensión de consejero": "La evidencia, en fin que desde mi mundo, yo no podía ayudarla en nada" (2008: 322). El narrador logra distanciarse del mundo sobrenatural que habita ahora Clarisa y reivindicarse en el mundo de los vivos, en un gesto que sugiere el final de su proceso de duelo: "Clarisa había encontrado su lugar. Bien. Pero yo, desde ahora, estaba haciendo lo posible por asegurar el mío" (2008: 327).

\subsection{Modalidad axiológica: espacio y el sistema de valores}

"Días entre los Wasi-Wano" también refleja las restricciones axiológicas que determinan la configuración de dominios cuyos valores se resisten a la norma. Doležel hace hincapié en la subjetivización de este sistema de valores: "valorization is strongly dependent on personality structure, and so the anxiological modalities are eminently prone to subjectivization: what is a value for one person might be a disvalue for another one" (1998: 124). Este relato retrata la casa de los tíos de la protagonista como un espacio de libertad y un estilo de vida que contrasta con la forma de vida del resto de la familia. Asimismo, la tribu amazónica a la que acceden por las noches ofrece un espacio idealizado al margen del desarrollo humano, que simboliza pureza y deseo y que confunde lo onírico con lo real ("Deseos, realidad... - repetía ahora-. Nada tan fácil como confundirlos”, 2015: 146). Como hemos establecido previamente, ese dominio se configura como refugio de los conflictos interpersonales de la cotidianidad adulta. La configuración espacial del cuento "Helicón" (1990) reitera esta modalidad axiológica. En este texto sobre la doble personalidad de Marcos, el apartamento del protagonista simboliza la rebelión contra - y liberación de - lo que la gente espera de él. Cuando toma el instrumento del helicón y deambula desnudo en su piso en lo que considera "una sesión única, incompartible, deliciosamente privada" (2015: 177), Marcos se transforma en Cosme, la versión subversiva de sí mismo. Ese piso personifica entonces el desorden, 
el caos y la suciedad que sus amigos condenan. Sin embargo, para el protagonista su casa deviene espacio "de delirio y de gozo, de vanidad y de soberbia" (2015: 178).

Cabe destacar, a modo de conclusión, que todos los espacios-santuario mencionados en este artículo reflejan aspectos de esta modalidad axiológica. El santuario ofrece protección al individuo del exterior y posibilita que esa vida diferenciada de la norma pueda existir. Como afirma el protagonista de "Helicón", estos espacios de la alteridad son "la parcela de privacidad absolutamente necesaria para que uno disfrute, por unos momentos, de la insustituible compañía de sí mismo" (2008: 177). Desde ellos personajes como Elba y Nona pueden "observar sin ser vistas" ("Mi hermana Elba", 2008: 67) ese mundo cotidiano del que se distancian y refugian.

\section{REFERENCIAS BIBLIOGRÁFICAS}

AnDRÉS-SuÁREZ, I. (2016). “'La habitación de Nona' de Cristina Fernández Cubas. Conjunción de lo fantástico y lo maravilloso". Ínsula: Revista de Letras y Ciencias Humanas 834, 41-43.

ApPADURAI, A. (1990). "Disjuncture and Difference in the Global Cultural Economy". Theory, Culture and Society 7.2-3, 295-310.

BнавHA, H. K. (1994). The Location of Culture. Londres: Routledge.

Bollnow, O. F. (2011 [1963]). Human Space. Londres: Hyphen Press.

Chevalier, J. \& Gheerbrandt, A. (1996). "Sanctuary”. En The Penguin Dictionary of Symbols, 824-825. Londres / Nueva York: Buchanan-Brown.

DoležEL, L. 1998. Heterocosmica: Fiction and Possible Worlds. Baltimore / Londres: Johns Hopkins University Press.

DuRAnd, G. (1992 [1960]). The Anthropological Structures of the Imaginary. Brisbane: Boombana Publications.

FERnÁndez CubAs, C. ([1980] 2008). "Mi hermana Elba”. En Todos los cuentos, 55-73. Barcelona: Tusquets. (2008 [1980]). “La ventana del jardín”. En Todos los cuentos, 43-54. Barcelona: Tusquets. (2008 [1990]). “El ángulo del horror”. En Todos los cuentos, 213-221. Barcelona: Tusquets. (2008 [1990]). “Helicón”. En Todos los cuentos, 169-190. Barcelona: Tusquets. (2008 [1994]). "El lugar”. En Todos los cuentos, 299-327. Barcelona: Tusquets. (2015). "La habitación de Nona". En La habitación de Nona, 13-44. Barcelona: Tusquets.

(2015). "Hablar con viejas". En La habitación de Nona, 45-56. Barcelona: Tusquets. (2015). "Interno con figura". En La habitación de Nona, 57-77. Barcelona: Tusquets. 
(2015). "Días entre los Wasi-Wano". En La habitación de Nona, 135-186. Barcelona: Tusquets.

FolKart, J. A. (2000). "Interpretations of Gender: Performing Subjectivity in Cristina Fernandez Cubas's 'Los altillos de Brumal'”. Anales de la Literatura Española Contemporánea 25.2, 389-416.

(2019). "On Doubling and Dis/ability: The Voice and View of Difference in the Fiction of Cristina Fernández Cubas". Symposium: A Quarterly Journal in Modern Literatures, 73.4, 219-232.

GARCÍA, P. (2015). "The Lighthouse (Edgar Allan Poe, 1849; Cristina Fernández Cubas, 1997): from the 'Egocentred' to a 'Geocentred' Analysis". En Shipwreck and Island Motifs in Literature and the Arts, B. Lejuez \& O. Springer (eds.), 97-108. Amsterdam: Brill / Rodopi.

Newman, D. (2006). "Borders and Bordering: Towards an Interdisciplinary Dialogue". European Journal of Social Theory 9.2, 171-186.

NuÑEZ DE LA FuENTE, S. (2019). "Resignificaciones de lo cotidiano en el espacio psicológico: 'La habitación de Nona' de Cristina Fernández Cubas". En Realidades fracturadas. Estéticas de lo insólito en la narrativa en lengua española (1980- 2018), N. Álvarez Méndez y A. Abello Verano (eds.), 111-123. Madrid: Visor.

RoAs, D. (2007). "El ángulo insólito: Cristina Fernández Cubas y lo fantástico”. En Cristina Fernández Cubas. Grand Séminaire de Neuchâtel, Coloquio Internacional Cristina Fernández Cubas, I. Andres-Suárez y A. Casas (eds.), 4160. Madrid: Arco / Libros.

(2011). Tras los límites de lo real: una definición de lo fantástico. Madrid: Páginas de Espuma.

(2019). "'The Terrible Convention Known as Time'. Chronological Distortions in the Narrative of Cristina Fernández Cubas". Bulletin of Hispanic Studies 96.6, 667-682.

RoAs, D.; Álvarez, A. y GarcíA, P. (2017). "Narrativa 1980-2015”. En Historia de lo fantástico en la cultura española contemporánea (1900-2015), David Roas (dir.), 195-214. Madrid: Iberoamericana Vervuert.

Rosello, M. \& Wolfe, S. T. (2017). "Introduction”. En Border Aesthetics, J. Schimanski \& S. F. Wolfe (eds.), 1-24. Nueva York: Berghahn Books.

Ryan, M.-L. (1991). Possible Worlds, Artificial Intelligence and Narrative Theory. Bloomington: Indiana University Press.

Schimanski, J. \& Wolfe, S. W. (2017). "Intersections: A Conclusion in the Form of a Glossary". En Border Aesthetics. J. Schimanski \& S. F. Wolfe (eds.), 147-169. Nueva York: Berghahn Books.

STRÜVER, A. (2005). Stories of the 'Boring Border': The Dutch-German Borderscape in People's Minds. Munster: Lit. Verlang. 
TALBOT, L. K. (1989). “Journey into the Fantastic: Cristina Fernández Cubas' 'Los altillos de Brumal". Letras Femeninas 15.1/2, 37-47.

Van Houtum, H.; Kramsch, O. \& Zierhoffer, W., EDS. (2005). B/ordering Space. Aldershot: Ashgate.

VAn Houtum, H. \& VAN NAERssen, T. (2002). "Bordering, Ordering and Othering", Tijdschrift voor Economische en Sociale Geografie 93.2, 125-36.

Walter, H. (2010). Beautiful Sanctuaries in Nineteenth-and Early-Twentieth-Century European Literature. Nueva York: Peter Lang.

ZatLin, P. (1996). "Amnesia, Strangulation, Hallucination and Other Mishaps: The Perils of Being Female in Tales of Cristina Fernandez Cubas". Hispania 79.1, 36-44.

Fecha de recepción: 20/11/2020

Fecha de aceptación: 05/03/2021 